\title{
Which factors are associated with the natural rate of haematoma resolution after clinical ICH? A pooled analysis of medical patients from the MISTIE and CLEAR trials
}

Lilli Nelson ${ }^{1,2}$, Calvin Heal ${ }^{3}$, W Andrew Mould ${ }^{4}$, Wendy Ziai ${ }^{4}$, Daniel F Hanley ${ }^{4}$, Adrian R Parry-Jones ${ }^{1,2}$, MISTIE \&

CLEAR Trial Investigators

\section{Background}

- The immune system facilitates haematoma resolution after intracerebral haemorrhage $(\mathrm{ICH})$ in the early (2-7 days) and late (8-30 days) subacute phases. ${ }^{1}$ Figure 1 demonstrates this.

- RBCs contain multiple neurotoxins and prompt clearance by activated microglia and macrophages may improve outcomes by limiting injury to the perihaematomal brain. $^{2}$

- The acute inflammatory response to $\mathrm{ICH}$ is thought to damaging and thus a putative key therapeutic target. However, it may be important in establishing prompt haematoma clearance and impeding this process may be detrimental.

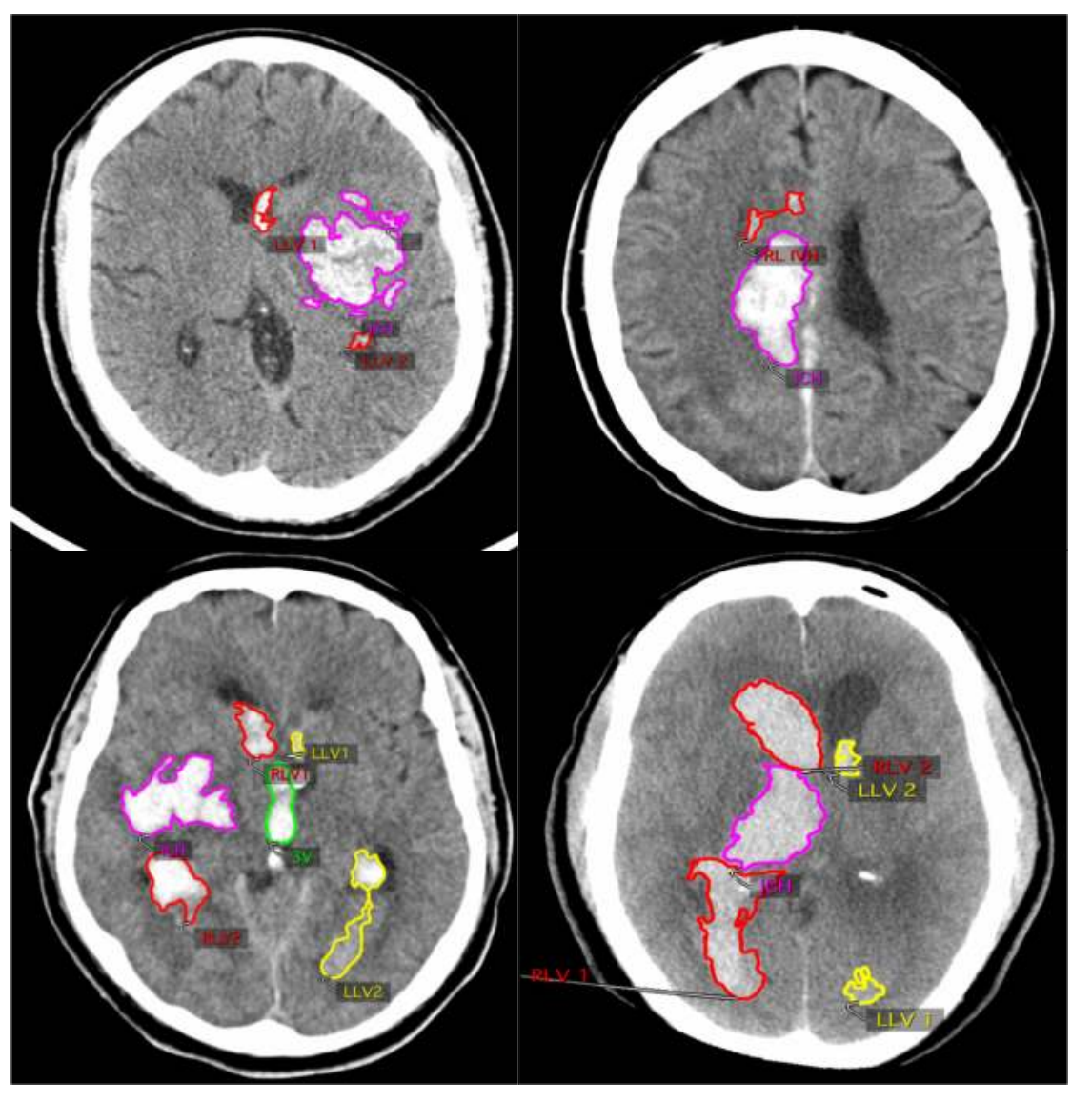

Fig 2: ICH outlined in magenta, CT scan slices on the left of the panel show an example of a relatively large $S A: V$ ratio, on the right a small one

\section{Aim}

Using serial CT imaging from control patients in the MISTIE and CLEAR trials, we sought to determine factors associated with the rate of haematoma resolution in $\mathrm{ICH}$, including markers of the peripheral and central inflammatory response, haematoma volume and haematoma surface area.

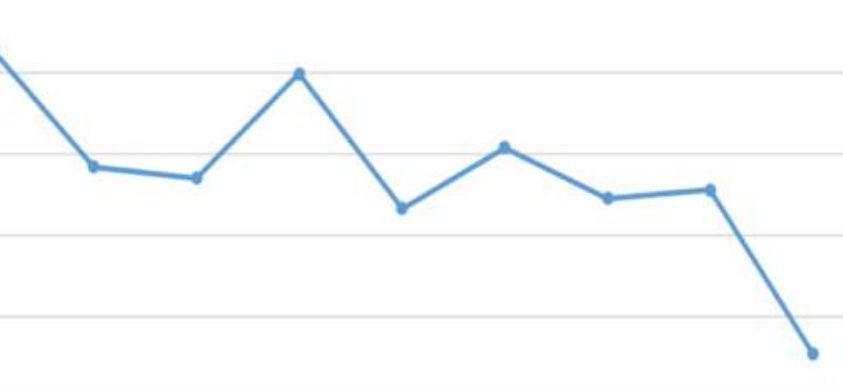

Fig 4: A typical trajectory of $\mathrm{ICH}$ volume resolution in from day 1-7 then day 30

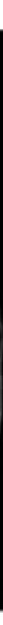

Fig 1: Resolution of a large ICH with intraventricular extension, showing daily $\mathrm{CT}$ scans from day 1 to 7 , with no detectable ICH by day 30

\section{Methods}

Patients randomised to standard care in MISTIE II (phase II) $)^{2}$ and MISTIE III and all patients in CLEAR III (phase III) ${ }^{4}$ multicenter, international RCTs with $\mathrm{ICH}$ volumes documented until day 30 were included in this retrospective analysis. Perihaematomal oedema $(\mathrm{PHO})$ at day 3 and daily $\mathrm{ICH}$ volume $(\mathrm{V})$ on all $\mathrm{CT}$ scans from diagnosis to day 7 then day 30 were measured by thresholdbased, semi-automated segmentation in OsiriX. (Fig 3) $\mathrm{ICH}$ surface area (SA) at baseline was calculated by the sum of [region-of-interest perimeter $x$ slice thickness] for each $\mathrm{ICH}$ then divided by volume to get $S A: V$ ratio.. Fig 2 shows the difference between a large SA and small SA in an $\mathrm{ICH}$ of the same volume. To remove early $\mathrm{ICH}$ expansion, volumes prior to day 3 were excluded. The mean ICH V gradient determined each patient's $\mathrm{ICH}$ resolution rate. A multifactoria linear regression model was then used to determine factors associated with resolution.

\section{Results}

Of 416 patients, we excluded 61 due to missing data and 89 without $\mathrm{ICH}$ volumes after day 20. 266 were in the final analysis. The mean rate of $\mathrm{ICH}$ clearance was $0.89 \mathrm{~cm}^{3} /$ day (SD: $0.58 \mathrm{~cm}^{3} /$ day). Example of a typical resolution trajectory is shown in fig 4. SA:volume ratio was associated with $\mathrm{ICH}$ resolution rate $(p=0.014)$ but no other factors previously associated with outcome were significantly associated. (Table 2)

\begin{tabular}{|l|l|l|l|l|}
\hline Characteristic & $\begin{array}{l}\text { MISTIE II } \\
(n=21)\end{array}$ & $\begin{array}{l}\text { MISTIE III } \\
(n=113)\end{array}$ & $\begin{array}{l}\text { CLEAR III } \\
n=132\end{array}$ & $\begin{array}{l}\text { Combined } \\
(n=266)\end{array}$ \\
\hline Age (SD) & $59.3(13.2)$ & $61(13.2)$ & $58.8(10)$ & $59 / 8(11.7)$ \\
\hline BP systolic mmHg & $141.1(18.9)$ & $137.4(16)$ & $146.7(22.1)$ & $142.3(20)$ \\
\hline White cell count & $10.7(4.1)$ & $11.8(3.7)$ & $12.2(4.2)$ & $12(4)$ \\
\hline Platelet count & $234.5(59)$ & $211.35(71.5)$ & $211.5(57.5)$ & $213.3(64)$ \\
\hline ICH Volume mI (SD) & $39.7(12.7)$ & $44.1(15.7)$ & $15.6(7)$ & $29.6(18.4)$ \\
\hline $\begin{array}{l}\text { PHO Volume ml } \\
(S D)\end{array}$ & $29.9(10.3)$ & $28.2(15.2)$ & $7.4(5.9)$ & $18(15.3)$ \\
\hline $\begin{array}{l}\text { ICH surface area } \\
\mathrm{cm} 2\end{array}$ & $53.2(33.9)$ & $71.6(23.2)$ & $32.09(15)$ & $50.55(28)$ \\
\hline $\begin{array}{l}\text { ICH Surface } \\
\text { area:volume }\end{array}$ & $1.4(1)$ & $1.8(1.7)$ & $2.4(1.3)$ & $2.1(1.5)$ \\
\hline ICH Location (\%) & $17(81)$ & $0(0)$ & $121(92)$ & $138(52)$ \\
\hline Deep & $4(19)$ & $113(100 \%)$ & $11(8)$ & $127(48)$ \\
\hline Lobar & & &
\end{tabular}

Table 1: Baseline characteristics of study populations from each

trial and combined

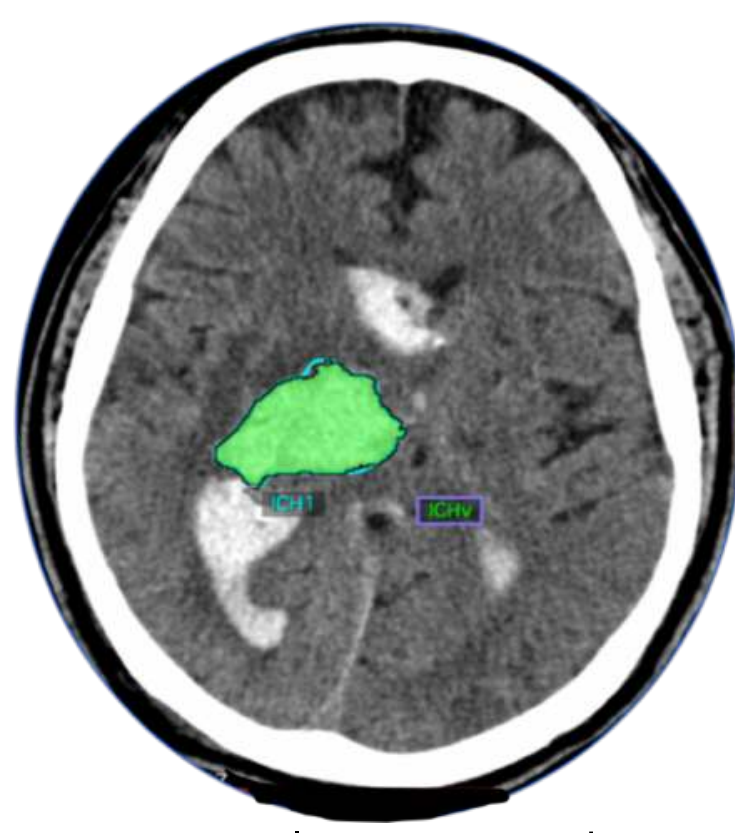

Fig 3: CT slice screenshot taken from OsiriX software

\section{Conclusion}

The only factor

significantly associated with the rate of clearance of ICH is their surface area:volume ratio. Markers of the acute inflammatory response are not associated with clearance, suggesting that inhibition of acute inflammation may not significantly slow $\mathrm{ICH}$ resolution rate

\begin{tabular}{|c|c|}
\hline $\begin{array}{c}\text { Factors associated with rate } \\
\text { of clearance }\end{array}$ & $\mathrm{p}$-Value \\
\hline Baseline ICH volume & 0.235 \\
\hline ICH surface area: volume & $\mathbf{0 . 0 1 4}$ \\
\hline Systolic Blood Pressure & 0.612 \\
\hline IVH Volume & 0.225 \\
\hline Age & 0.421 \\
\hline Baseline WCC & 0.961 \\
\hline Baseline Platelet Count & 0.288 \\
\hline PHO Volume & 0.655 \\
\hline Presence of Infection & 0.84 \\
\hline Statins & 0.597 \\
\hline Anticoagulants & 0.555 \\
\hline \multicolumn{2}{|c}{}
\end{tabular}

Table 2: Factors included in our linear regression model with $p$-values. 